\title{
Glucose Metabolism during Liver Transplantation in Dogs
}

\author{
Andre M. DeWolf, MD, Yoo G. Kang, MD, Satoru Todo, MD, Igal Kam, MD, \\ Antonio J. Francavilla, MD, Lorenzo Polimeno, PhD, Steve Lynch, MD, and \\ Thomas E. Starzl, MD, PhD
}

DeWOLF AM, KANG YG, TODO S, KAM I,

FRANCAVILLA AJ, POLIMENO L, LYNCH S,

STARZL TE. Glucose metabolism during liver

transplantation in dogs. Anesth Analg 1987;66:76-80.

Arterial and hepatic venous blood lezels of glucose were studied in 12 dogs during orthotopic liver transplantation performed under ketamine anesthesia without exogenous glucose administration. During the early part of surgery, arterial blood glucose levels were stable: $161 \pm 12 \mathrm{mg} / \mathrm{dl}$ (mean \pm SEM) after laparotomy and $183 \pm 16 \mathrm{mg} / \mathrm{dl} 5 \mathrm{~min}$ before the anhepatic stage. During the anhepatic stage, arterial blood glucose levels decreased progressively to $135 \pm$ 9 and $88 \pm 8 \mathrm{mg} / \mathrm{dl}, 5 \mathrm{~min}$ in the anhepatic stage and 5 min before reperfusion of the graft lizer, respectively $(P<$ $0.05)$. Reperfusion of the graft liver resulted in an increase in arterial glucose levels to $206 \pm 17$ and $240 \pm 24 \mathrm{mg} / \mathrm{dl}$, 5 and 30 min after reperfusion, respectively $(P<0.05)$.
Hepatic venous blood glucose leiels increased after reperfusion ( $405 \pm 37$ and $346 \pm 41 \mathrm{mg} / \mathrm{dl}, 5$ and $30 \mathrm{~min}$ after reperfusion, respectively) and u'ere significantly higher than in arterial blood $(P<0.05)$. Arterial plasma insulin, measured in five animals, did not change significantly during the procedure, whereas plasma glucagon levels, stable during the preanhepatic and anhepatic stages, increased steadily after reperfusion of the graft lizer, from $66.1 \pm 14.2$ to $108.4 \pm 38.1 \mathrm{pg} / \mathrm{ml}(P<0.05)$. This study show' that in dogs with ketamine anesthesia mild hypoglycemia occurs during the anhepatic stage of licer transplantation without exogenous glucose administration followed by hyperglycemia on reperfusion of the graft liver, possibly secondary to the release of glucose from the donor liver.

Key Words: ANESTHESIA-liver transplantation. LIVER-transplantation. METABOLISM-glucose.
Significant improvements have been made recently in the surgical and anesthetic management of patients undergoing liver transplantation $(1,2)$. However, understanding of glucose metabolism during liver transplantation is still incomplete. Aldrete et al. saw hypoglycemia frequently, especially during the anhepatic stage of the procedure, and advised that large amounts of exogenous glucose be administered during orthotopic liver transplantation in humans (3). They ascribed the low levels of glucose to the absence of the liver, the main producer of blood glucose. Others have reported that hypoglycemia did not occur when small

Supported in part by research grants from the Veterans Administration; by Project Grant No. AM-29961 from the National Institutes of Health; and by Grant No. RR-00084 from the General Clinical Research Centers Program of the Division of Research Resources, National Institutes of Health, Bethesda, Maryland.

Received from the Departments of Anesthesiology and Surgery, Presbyterian-University Hospital, University of Pittsburgh, Pittsburgh, Pennsylvania. Accepted for publication July 8, 1986.

Address correspondence to Dr. Kang, Department of Anesthesiology, Presbyterian-University Hospital, DeSoto at O'Hara Streets, Pittsburgh, Pennsylvania 15213. amounts of exogenous glucose were administered $(4,5)$. Tullock et al. reported that without administration of exogenous glucose other than that in transfused blood, blood glucose levels remained within an acceptable range during the preanhepatic and anhepatic stages, but that hyperglycemia of more than $200 \mathrm{mg} / \mathrm{dl} \mathrm{oc-}$ curred after reperfusion of the graft liver (4).

These differences in clinical experience remain unexplained; glucose metabolism may have been different among individual recipients, and intraoperative management also may have been different. To investigate intraoperative glucose metabolism, we measured blood levels of glucose, insulin, and glucagon in healthy dogs undergoing liver transplantation without exogenous glucose infusion.

\section{Methods}

Orthotopic liver transplantation was performed in 12 adult beagle dogs, weighing between 11.0 and 14.0 $\mathrm{kg}$ (mean $11.9 \mathrm{~kg}$ ). The animals fasted overnight. Anesthesia was induced and maintained with intra- 
Table 1. Laboratory Data during Liver Transplantation in 12 Dogs

\begin{tabular}{|c|c|c|c|c|c|c|}
\hline \multirow[b]{2}{*}{ Variable } & \multicolumn{2}{|c|}{ Preanhepatic stage } & \multicolumn{2}{|c|}{ Anhepatic stage } & \multicolumn{2}{|c|}{ Postanhepatic stage } \\
\hline & $1+30 \mathrm{~min}$ & $\mathrm{Il}-5 \mathrm{~min}$ & $\mathrm{II}+5 \min$ & III $-5 \min$ & $\mathrm{III}+5 \min$ & $111+30 \mathrm{~min}$ \\
\hline Body temperature $\left({ }^{\circ} \mathrm{C}\right)$ & $36.0 \pm 0.3$ & $35.1 \pm 0.2^{\prime \prime}$ & $34.2 \pm 0.3^{n}$ & $33.7 \pm 0.3^{\prime \prime}$ & $32.9=0.4^{\prime \prime \prime}$ & $32.8=0.4^{\prime \prime \prime}$ \\
\hline \multicolumn{7}{|l|}{ Arterial blood } \\
\hline Hematocrit (c) & $+4.3 \pm 1.6$ & $42.4 \pm 1.8$ & $34.2 \pm 2.3$ & $34.1=1.7^{\prime \prime}$ & $28.5=2.3^{u}$ & $27.3=1.9 . \%$ \\
\hline $\mathrm{pH}^{\mathrm{H}}$ & $7.43 \pm 0.02$ & $7.43 \pm 0.02$ & $7.42 \pm 0.02$ & $7.34=0.02^{\prime \prime}$ & $7.30=0.02^{n \cdot n}$ & $7.23=0.02$ \\
\hline$P a c c=(m m ~ H g)$ & $29.3 \pm 1.5$ & $27.3 \pm 1.2$ & $25.0 \pm 1.5^{\prime \prime}$ & $26.4=1.8^{\prime \prime}$ & $24.6=1.5^{a t h}$ & $26.5 \pm 2.0^{\prime}$ \\
\hline$P a c=(\mathrm{mm} \mathrm{Hg})$ & $141.1 \pm 11.5$ & $147.7 \pm 12.1$ & $148.4 \pm 7.0$ & $148.8=6.7$ & $154.7=7.6^{a, t h}$ & $154.9=9.5^{\prime \prime \prime}$ \\
\hline Base deficit & $3.7 \pm 0.7$ & $4.3 \pm 0.6$ & $6.3 \pm 0.6^{\prime}$ & $9.7 \pm 0.8^{\prime \prime}$ & $12.8=0.8^{n, t}$ & $14.8 \pm 0.8^{n}$ \\
\hline $\mathrm{Na}(\mathrm{meq} / \mathrm{L})$ & $146.7 \pm 0.8$ & $146.3 \pm 1.1$ & $142.1 \pm 0.8^{4.11}$ & $144.4=1.4^{\prime 2}$ & $141.6=1.3^{a, b}$ & $1+2.2 \pm 1.3^{\prime \prime}$ \\
\hline $\mathrm{K}(\mathrm{meq} / \mathrm{L})$ & $2.53 \pm 0.08$ & $2.60 \pm 0.12$ & $2.81 \pm 0.10^{\prime}$ & $2.78 \pm 0.08^{a}$ & $4.10 \pm 0.27^{a, b}$ & $3.30=0.20^{n .}$ \\
\hline \multicolumn{7}{|l|}{ Hepatic venous blood } \\
\hline $\mathrm{pH}$ & $7.42 \pm 0.02$ & $7.40 \pm 0.02$ & - & - & $7.15=0.03^{a, \prime}$ & $7.14 \pm 0.04^{a . .}$ \\
\hline$\Gamma_{\mathrm{rCO}}(\mathrm{mm} \mathrm{Hg})$ & $32.2 \pm 1.4$ & $32.5 \pm 1.8$ & - & - & $44.2 \pm 2.8^{\prime \prime}$ & $44.5 \pm 3.8^{a . t}$ \\
\hline$P v(c)=(\mathrm{mm} \mathrm{Hg})$ & $57.8 \pm 6.3$ & $43.8 \pm 2.0^{1 . c}$ & - & - & $21.4=2.2^{a t . i}$ & $26.0 \pm 3.2^{a, t}$ \\
\hline Base deficit & $3.3 \pm 0.6$ & $3.8 \pm 0.5$ & - & - & $12.4=1.1^{\prime \prime}$ & $12.8 \pm 1.3^{11.4}$ \\
\hline $\mathrm{Na}(\mathrm{meq} / \mathrm{L})$ & $147.0 \pm 0.9$ & $145.5 \pm 1.1^{n}$ & - & - & $140.9=1.1^{\prime \prime}$ & $143.2 \pm 1.2^{a}$ \\
\hline$K(\mathrm{meq} / \mathrm{L})$ & $2.63 \pm 0.14$ & $2.87 \pm 0.23^{c}$ & - & - & $4.92 \pm 0.50^{\prime \prime . c}$ & $3.60 \pm 0.26^{a, c}$ \\
\hline
\end{tabular}

Values are mean $=\mathrm{SEM}$

Different from the values at $1+30 \mathrm{~min}$

Different from the values at $11 \mathrm{l}-5 \mathrm{~min}$

Different from the corresponding values in arterial blood.

$(4,5)$

on of

lood,

table

ages,

II oc-

main

I dif-

sera-

t. To

we

glu-

inta-

in 12

14.0

ight.

ntra- venous ketamine ( $2 \mathrm{mg} / \mathrm{kg}$ followed by $1 \mathrm{mg} / \mathrm{kg}$ every 20-30 min), plus pancuronium bromide for muscle relaxation. The dogs were mechanically ventilated with $\mathrm{Fl}_{\mathrm{O}_{2}}$ of 0.3 and end-tidal $\mathrm{CO}_{2}$ was maintained between 4 and $5 \%$. Femoral arterial and jugular venous catheters were inserted for blood sampling and monitoring of arterial and central venous pressures. Crystalloid solution without glucose (Plasma-Lyte A, Travenol Laboratories, Inc., Deerfield, IL) was infused at a rate of $40 \mathrm{ml} \cdot \mathrm{kg}^{-1} \cdot \mathrm{hr}^{-1}$. Dopamine was infused to maintain mean arterial pressure above 70 torr. The surgical technique has been reported elsewhere (6). Surgery in the donor and recipient was synchronized to minimize donor organ ischemic time. The operation has three stages: a preanhepatic stage (stage I), from the induction of anesthesia to hepatectomy; an anhepatic stage (stage II), from hepatectomy to reperfusion of the graft; and a postanhepatic stage (stage III), from reperfusion of the graft liver to the end of surgery. The donor organs were preserved with cold $\left(0-4^{\circ} \mathrm{C}\right)$ lactated Ringer's solution. In all recipient dogs, venous bypass (Bio-Medicus, Inc., Minnetonka, MN) was used during the anhepatic stage of surgery to divert blood from the splenic and femoral veins to the jugular vein. The graft liver was reperfused by unclamping the portal vein and the supra- and infrahepatic inferior vena cava after the vascular anastomoses were completed. Throughout the procedure, no glucose was administered to the recipient dogs: Neither the administered electrolyte solution nor the organ preservation solution contained glucose, and no blood was transfused during the study.

In the preanhepatic stage, femoral arterial and hepatic venous blood samples were drawn $30 \mathrm{~min}$ after laparotomy $(\mathrm{I}+30 \mathrm{~min})$ and $5 \mathrm{~min}$ before the beginning of the anhepatic stage (II $-5 \mathrm{~min}$ ). Hepatic venous blood samples were taken by venipunctures at the proximal part of the hepatic vein to avoid contamination by blood from the inferior vena cava. During the anheptic stage, arterial blood was sampled 5 min after onset (II $+5 \mathrm{~min}$ ) and $5 \mathrm{~min}$ before reperfusion of the graft liver (III - $5 \mathrm{~min}$ ). In the postanhepatic stage, arterial and hepatic venous blood samples were collected $5 \mathrm{~min}$ (III $+5 \mathrm{~min}$ ) and $30 \mathrm{~min}$ (III $+30 \mathrm{~min}$ ) after reperfusion of the graft liver. The blood samples were analyzed to determine glucose levels, arterial blood-gas tensions and acid-base state, hematocrit, and levels of $\mathrm{Na}$ and $\mathrm{K}$. Blood glucose levels were determined using the glucose oxidase test (YSI model 23 A glucose analyzer, Yellow Springs Instruments Co., Yellow Springs, $\mathrm{OH})$. Arterial insulin and glucagon levels were measured in five animals during the preanhepatic and postanhepatic stages using radioimmunoassay technique (Serono Diagnostics, Braintree, MA). Data are reported as mean \pm SEM. Data were analyzed by analysis of variance for repeated measures (ANOVA), and specific differences were assessed with the StudentNewman-Keuls test; $P<0.05$ was considered statistically significant. 


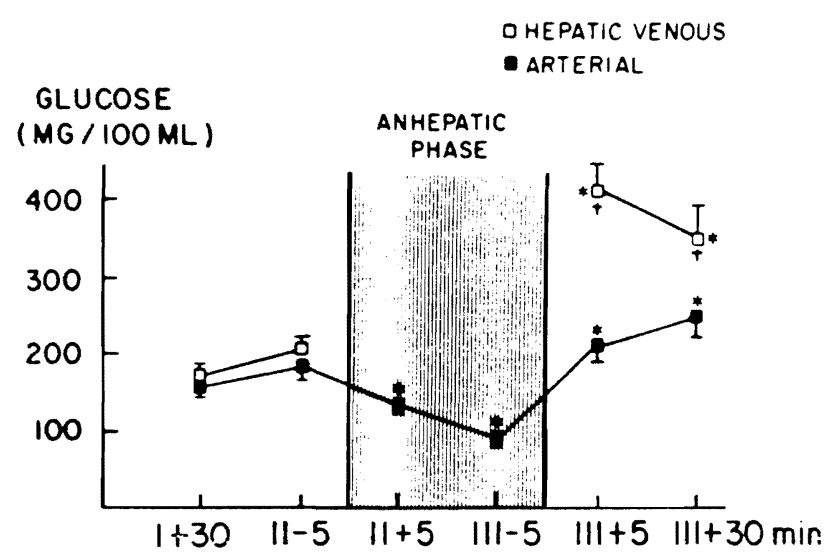

Figure 1. Blood glucose levels in arterial and hepatic venous blood during liver transplantation in 12 dogs. (Values are mean \pm SEM.) (*)Different from the values in the preanhepatic stage. (+)Different from the corresponding values in arterial blood.

\section{Results}

The preanhepatic stage lasted $78 \pm 19 \mathrm{~min}$, the anhepatic stage $47.5 \pm 17 \mathrm{~min}$, and the postanhepatic stage $92 \pm 24 \mathrm{~min}$. Intraoperatively, cardiovascular function was relatively stable except during the second half of the anhepatic stage and the first $15 \mathrm{~min}$ after reperfusion. Dopamine was infused in all animals to maintain mean arterial pressure above $70 \mathrm{~mm}$ $\mathrm{Hg}$ during the unstable period, the dose ranging from 5 to $20 \mu \mathrm{g} \cdot \mathrm{kg}^{-1} \cdot \mathrm{min}^{-1}$. Laboratory data are shown in Table 1. All variables were within the normal range and stable in the preanhepatic stage. During the anhepatic stage, body temperature, hematocrit, and $\mathrm{pH}$ decreased. Reperfusion of the grafted liver caused a further decrease in body temperature, hematocrit, and $\mathrm{pH}$. Similar changes occurred in hepatic venous blood after reperfusion, although hepatic venous blood was significantly more acidotic and had a higher potassium concentration than arterial blood.

Intraoperative blood glucose levels are presented in Figure 1. During the preanhepatic stage (stage I), arterial glucose levels were $161 \pm 12$ and $183 \pm 16$ $\mathrm{mg} / \mathrm{dl}$, and hepatic venous glucose levels were $170 \pm$ 12 and $202 \pm 15 \mathrm{mg} / \mathrm{dl}$. The latter were slightly higher, but not significantly so. During the anhepatic stage (stage II), mean blood glucose levels decreased progressively to $135 \pm 9 \mathrm{mg} / \mathrm{dl}$ after initiation of the anhepatic stage $(P<0.05)$, and to $88 \pm 8 \mathrm{mg} / \mathrm{dl} \mathrm{im}$ mediately before reperfusion of the graft liver $(P<$ 0.05). Blood glucose levels were between 60 and 70 $\mathrm{mg} / \mathrm{dl}$ in three animals and 70 and $80 \mathrm{mg} / \mathrm{dl}$ in four animals at the end of the anhepatic stage. Blood glu-

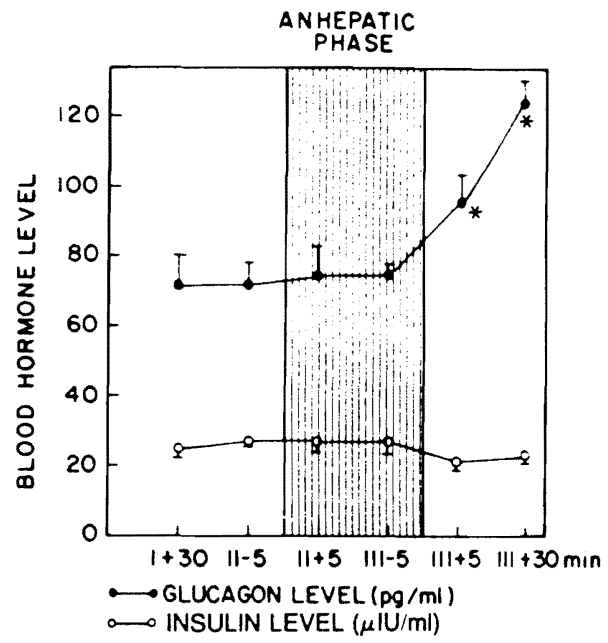

Figure 2. Arterial blood levels of glucagon and insulin during liver transplantation in five dogs. (Values are mean \pm SEM.) (*)Different from the values in the preanhepatic and anhepatic stages.

cose levels, increased with reperfusion of the graft liver (stage III), were significantly higher in hepatic venous blood than in arterial blood: $206 \pm 17 \mathrm{mg} / \mathrm{dl}$ at III $+5 \mathrm{~min}$ and $240 \pm 24 \mathrm{mg} / \mathrm{dl}$ at III $+30 \mathrm{~min}$ in arterial blood, and $405 \pm 37 \mathrm{mg} / \mathrm{dl}$ at III $+5 \mathrm{~min}$ and $346 \pm 41 \mathrm{mg} / \mathrm{dl}$ at III $+30 \mathrm{~min}$ in hepatic venous blood. Plasma insulin levels, initially $24.3 \pm 1.0$ $\mu \mathrm{IU} / \mathrm{ml}$, did not change significantly during the entire observation period (Fig. 2). Plasma glucagon levels did not change during the preanhepatic or anhepatic stage $(71.3 \pm 20.5$ and $73.9 \pm 27.4 \mathrm{pg} / \mathrm{ml}$, respectively) but increased steadily after reperfusion of the graft liver, reaching peak $30 \mathrm{~min}$ after reperfusion $(123.5 \pm 33.6 \mathrm{pg} / \mathrm{ml})$, significantly above preanhepatic and anhepatic levels. In five animals blood glucose levels were compared with the glucagon/insulin ratios, but the correlation was very poor $\left(r^{2}=0.02\right)$. On completion of the study, all dogs were transfused with whole blood obtained from the organ donor dogs; ten animals received 2 units and two animals received 3 units. Two animals died of pulmonary edema and pneumothorax at the end of surgery. Three animals died postoperatively within $48 \mathrm{hr}$ and seven animals lived more than 6 postoperative days.

\section{Discussion}

The liver is responsible for uptake, storage, and release of glucose, and for gluconeogenesis. The blood level of glucose is determined by the balance between 
release of glucose into the blood stream and glucose utilization by the body. These are influenced by, among other factors, the activities of insulin, glucagon, catecholamines, and glucocorticoids. Hepatic uptake of glucose and glycogen synthesis are enhanced by insulin. Glucagon stimulates gluconeogenesis and glycogenolysis and thereby increases hepatic output of glucose. Secretion of glucagon, epinephrine, and growth hormone can increase in response to hypoglycemia and stress. The liver is exposed to high concentrations of insulin and other hormones in portal blood, and the effects of these hormones on hepatic glucose metabolism may be more important than has been recognized. Because of the major role of the liver in glucose homeostasis, significant changes in blood glucose levels are expected during liver transplantation in experimental animals and in patients.

In the animals studied, exogenous glucose administration, including that in blood transfusions, was completely avoided. The dogs had normal preoperative hematocrits, and blood loss during surgery was minimal until the postanhepatic stage, so transfusion could be delayed until the study was completed ( 30 min after reperfusion). In the preanhepatic stage, glucose levels were stable, and arterial and hepatic venous blood glucose levels were similar, but initiation of venous bypass decreased hematocrit and blood glucose levels significantly. These decreases were most likely due to hemodilution from the priming solution in the bypass system, $250 \mathrm{ml}$ balanced electrolyte solution. As the anhepatic stage progressed, blood glucose levels decreased further, possibly owing to continuing glucose utilization with decreased glucose production. In the present study the mean duration of the anhepatic stage was $47.5 \mathrm{~min}$, about one-half the $93 \mathrm{~min}$ reported in clinical cases (7). With a longer anhepatic stage, glucose levels may decrease further in animals. Plasma insulin and glucagon levels did not change during the preanhepatic and anhepatic stages. Although blood glucose levels decreased during the anhepatic stage, the levels may not have been low enough to cause glucagon release.

The changes in metabolic variables with reperfusion are similar to results obtained during human liver transplantation: metabolic acidosis, hyperkalemia, hemodilution, and hypothermia caused by the release of cold, hyperkalemic, acidotic fluid from the graft liver (8-10). Reperfusion of the liver significantly increased arterial blood glucose levels. The increase may have been secondary to a massive release of glucose from the newly implanted liver, as indicated by the higher glucose level in hepatic venous blood compared with that in arterial blood and by the association of the increasing arterial glucose level with the decreasing hepatic venous glucose level. A similar observation has been made by Halliday et al., who demonstrated progressively increasing glucose levels in the hepatic venous blood of the continuously perfused pig donor liver (11). Ischemic injury in the hepatocytes may have damaged cell membrane permeability, which allowed the release of intracellular glucose (12). It is interesting to note that plasma glucagon levels progressively increased after reperfusion despite arterial hyperglycemia. The increase in glucagon levels may have been caused by delayed release of glucagon in response to a low blood sugar level during the anhepatic stage or, alternatively, the release of glucagon may have played a role in the postreperfusion arterial hyperglycemia. However, a positive relationship between blood glucose levels and glucagon/insulin ratios was not seen in this study, although the lack of correlation could be due to the small number of animals studied. The administration of dopamine could have increased the secretion of glucagon, but only minimally. Thus, sudden hyperglycemia, especially in hepatic venous blood, that occurred within $5 \mathrm{~min}$ after reperfusion is unlikely to be hormonal in origin. Hypothermia in the recipient dogs could have decreased glucose utilization, and the relative ischemia of the donor liver occurring after reperfusion may also have affected the graft liver's sensitivity to hormones and intracellular enzymes responsible for glycogenolysis. This study was limited to $30 \mathrm{~min}$ after reperfusion; glucose metabolism in the postoperative period requires further investigation. It is also unknown whether or not the amount of glucose released from the reperfused graft liver has any prognostic value with respect to functional recovery of the organ, if postreperfusion hyperglycemia were caused by ischemic damage of the donor liver.

Similar changes in glucose homeostasis are expected to be seen in patients receiving liver transplants, although there are several differences between our experimental design and clinical patient care. In the animals studied, anesthesia was maintained with ketamine, which could have increased blood glucose level indirectly by releasing catecholamines (13), and the duration of the anhepatic stage was shorter than that in patients, which might have led to the higher glucose level than the values expected in patients. However, hyperglycemia is more likely to occur in patients undergoing liver transplantation. Glucose metabolism is altered in patients with chronic liver disease, and high levels of circulating insulin are common owing to hypersecretion of insulin or inadequate hepatic clearance of insulin (14), but these patients 
are known to be resistant to insulin action (15). A high plasma glucagon level is frequently observed, caused by hypersecretion and the effects of portasystemic shunting (16). Clinically, glucose intolerance and higher than normal blood glucose levels are not unusual. In patients, the intraoperative transfusion of blood preserved in dextrose solution (CPDA-1), which contains $200 \mathrm{mg} / \mathrm{dl}$ of glucose, is unavoidable, and flushing of preservation solution (Collins' solution, glucose $3.75 \%$ ) into the systemic circulation may supply enough glucose to maintain adequate glucose levels. The high catecholamine levels observed in patients receiving liver transplants (Uram et al., unpublished data, 1984) may counteract the peripheral effects of insulin, and possible disturbances of the hormonal balance between insulin and glucagon may occur. Furthermore, the donor organ with a longer ischemic time in patients $(4-8 \mathrm{hr})(1)$ may release more glucose on reperfusion, whereas, glucose utilization is decreased by frequent inadvertent hypothermia. The effects of postreperfusion hyperglycemia on urine output and its composition were not determined in the present study. Hyperglycemia exceeding the transport maximum of the renal tubules may cause glucosuria and osmotic diuresis.

In conclusion, this study showed minimal hypoglycemia during the anhepatic stage and hyperglycemia after reperfusion of the graft liver in healthy dogs undergoing liver transplantation, without exogenous glucose administration. The postreperfusion hyperglycemia appears to be secondary to a release of glucose from the newly grafted liver. The results suggest that hypoglycemia is less likely in patients when glucose is administered by transfusion of banked blood, and hyperglycemia may occur if additional exogenous glucose is given, especially after reperfusion of the graft liver.

The authors thank Marc Zapp and Frank McSteen for their technical assistance, and Lisa Cohn for her editorial help.

\section{References}

1. Starzl TE, Iwatsuki S, Van Thiel DH, et al. Evolution of liver transplantation. Hepatology 1982;2:614-636.

2. Starzl TE, Iwatsuki S, Shaw BW Jr, Gordon RD. Orthotopic liver transplantation in 1984. Transplant Proc 1985;17:250-258.

3. Aldrete JA. Liver transplantation: Intraoperative and anesthetic management. In: Arias A, Llaurado R, Nalda M, eds. Recent progress in anaesthesiology and resuscitation. Excerpta Medica: Amsterdam, 1975;387-391.

4. Tullock WC, Pinsky MR, Shaw BW, Martin DJ. Metabolic changes during the anhepatic phase of liver transplantation (Abstr). Anesthesiology 1984;61:A271.

5. Borland LM, Roule M, Cook DR. Anesthesia for pediatric orthotopic liver transplantation. Anesth Analg 1985;64:117-124.

6. Todo S, Kam I, Lynch S, Starzl TE. Animal research in liver transplantation with special reference to the dog. Semin Liver Disease 1985;4:309-317.

7. Shaw BW, Martin DJ, Marquez JM, et al. Venous bypass in clinical liver transplantation. Ann Surg 1984;200:524-534.

8. Lindop MJ, Farman JV, Smith MF. Anaesthesia: Assessment and intraoperative management. In: Calne RY, eds. Liver transplantation. Grune \& Stratton: New York, 1983:121-143.

9. Martin DJ, Marquez JM, Kang YG, Shaw BW, Pinsky MR. Liver transplantation: Hemodynamic and electrolyte changes seen immediately following revascularisation (Abstr). Anesth Analg $1984 ; 63: 246$

10. Carmichael FJ, Lindop MJ, Farman JV. Anesthesia for hepatic transplantation: Cardiovascular and metabolic alterations under their management. Anesth Analg 1985:64:108-116.

11. Halliday JP, Sheil R, Hensley WJ, Bookallil J, Wotherspoon GP. Biochemical aspects of experimental hepatic allotransplantation. Arch Surg 1974;108:75-80.

12. Lambotte L, Wojcik S, Pontegnie-Istace S. Investigations on the mechanisms of action of hyperosmolar intracellular solutions used in liver preservation. In: Pegg DE, Jacobson IA, eds. Organ preservation Il. Churchill Livingstone: London, 1979: 292-303

13. Zsigmond EK, Domino EF. Clinical pharmacology and current use of ketamine. In: Aldrete JA, Stanley TH, eds. Trends in intravenous anesthesia. Year Book Medical Publishers: Chicago, 1980:283-328.

14. Collins JR, Lacy WW, Stiel JN, Crofford OB. Glucose intolerance and insulin resistance in patients with liver disease. Arch Int Med 1970;126:608-614.

15. Flier JS, Kahn CR, Roth J. Receptors, antireceptor antibodies and mechanisms of insulin resistance. $N$ Engl J Med 1979;300:413-419.

16. Marco J, Diego J. Villanueba ML, Diaz-Fierros M, Valverde I, Segovia JM. Elevated plasma glucagon levels in cirrhosis of the liver. N Engl J Med 1973;289:1107-1111. 